\title{
PHYSICS AND THE FOUNDATIONS OF ECONOMIC SCIENCE: COMMENTS IN MEMORY OF ILYA PRIGOGINE
}

RICHARD H. DAY

Received 11 December 2003

This paper discusses how the concepts of nonlinearity, discrete dynamics, chaos, and emergent order that Ilya Prigogine advanced correspond to similar ideas involved in the adaptive, evolutionary branch of economics.

\section{Ilya Prigogine and interdisciplinary science}

Ilya Prigogine must always have had his eye out for kindred spirits, individuals who loved science - all science - and who were contributing to some science in particular. That may be why he appeared so often at multidisciplinary conferences and why he sponsored so many such events himself. I first met him at one such conference, one devoted to nonlinear dynamics sponsored by the U. S. Department of Transportation under the leadership of Robert Crosby. That institution's immediate concern was the growth of cities and the complex, developing transportation networks that cities require. Crosby had already contracted with Ilya's Solvay Institute to study the phenomenon. Bob's conference brought mathematicians, physicists, and regional scientists together to consider the methodological problems involved, to inform one another of the various approaches being taken already, or that seemed to have potential, and to expose commonalities among them: nonlinearities of causal structure and complex patterns of system development over time and space (see [4]).

There followed a series of even more inclusive multidisciplinary conferences sponsored by Prigogine at his centers in Brussels and Austin with specialists in mathematics, physics, biology, and economics who, in spite of their varied interests and expertise, shared common scientific visions. These conferences provided an outlet for research that was pressing beyond the boundaries of "standard" science. They helped establish a critical mass of intellectual work on nonlinear dynamics and evolutionary processes that has itself become a main stream. Many who might have remained in their lonely quests thus found a congenial intellectual home. Prigogine successfully created a main stream into which his own work could flow and in which many lesser fish could swim (see $[1,4,5])$.

These informal remarks consider the nature of physics, mathematics, and economics vis-à-vis the complex, evolutionary world which was Ilya's life work to comprehend. 


\section{Time, instability and novelty}

How can we relate these various meanings of time-time as motion, time related to irreversibility as in thermodynamics, time as history as in biology and sociology?

Prigogine [12]

Prigogine shared with many philosophers an obsession with time. What is it? Is it reversible or irreversible? Is it something real, something that could itself be explained by or inferred from more fundamental phenomena? Is it simply another dimension like space, so that its passing is merely an illusion?

Whatever it is, it is an ordering of events that are experienced and remembered or recorded. Without it we should not carry in our minds the partially remembered story of our lives, no joys to be savored, no lessons to be learned, no regrets to be endured: we should have no past. We should not be able to orient our actions toward any anticipated goal, for there could be no anticipation, no problems to solve, no choices to be made; in short, no future. So time exists for us and it has value, like any good in short supply.

Given a finite chain of time-ordered events associated with a distinguishable process and given quantitative indexes that describe the process at each "time," one can inquire about the past or the future of the quantitative measures or states. Are they growing or shrinking, or some growing and some shrinking? Are they heading for a steady state where all the indexes would be changing at exactly the same rate, proportional to one another? Are they heading for a stationary state where the indexes become constant? Or, in between these extremes, are they approaching some intertemporal pattern that repeats itself at regular intervals — or fails ever to repeat itself, always generating states that form no identifiable pattern, that do not converge to stationary, steady, or periodic states? These are the mathematical questions posed in the dynamic analysis of observable, quantifiable processes.

If a process converges to a periodic, steady, or stationary state, it is asymptotically stable, becoming ever more predictable with the passage of time. If on the other hand a process is irregular (chaotic), its trajectories are unstable in that its states do not converge to predictable patterns, yet are stable in the sense of being confined, that is, bounded and predictable in a statistical, probabilistic sense. Finally, quantum processes are defined in terms of "waves" or distributions of conceptual events, distributions that change their "shape" over time so that the chance of experiencing (at the human scale) any given event may itself change over time.

The instability that arises in human experience would seem to be pervasive: it is far more difficult to predict human events that will take place in the future than to explain those that occurred in the past. Wassily Leontief, in a perceptive essay, implied that human history was essentially unstable and suggested that, like geologists and paleontologists, the historian interested in isolating the cause of changes should start with a given set of known recent events, then identify their immediate antecedents, rather than start with an early situation and try to explain what happened years later as a result (see $[9,10])$. Thus, to provide a variation on Leontief's parable, if the historian wanted to explain why Alexander's empire split into three soon after his death, it would be futile to derive an 
explanation based on the battle where Alexander received his fateful injury. Rather, going backwards from the split through the sequence of events that preceded it, finally arriving at the injury that led to his demise before the structure of empire could be solidified, one would see that one event inevitably precedes another, even if the ultimate "cause" was Alexander's hubris in scaling the Mallian fortress wall and assaulting the defenders by himself (see [2, page 311ff]). The successive swallowing up of Greece in the Roman, Byzantine, and Ottoman Empires follows in no obvious way from that isolated event in Asia that preceded them. Yet, proceeding backwards, an understanding might emerge as to why history churned out that sequence of events and not another.

As a kind of mathematical "outline of history," I constructed a discrete time "regular mountainous" map that generates chaotic paths of population numbers through the mega stages of demoeconomic development. These time paths mimic in a qualitative way the progression of the world's population through the hunting and food collecting band, settled agriculture, city states, trading empires, the nation state, and the global information economy with growth and fluctuations in population numbers within stages, and with switching to more advanced or reverting to less advanced stages, more or less as it actually occurred in the records archaeologists and historians have constructed. Defining a scenario as a particular sequence of stages and using backwardly iterated, multivalued maps, it is possible in principle to derive the set of initial conditions in the first stage that would lead to any given hypothetical scenario. Contrastingly, picking initial conditions that would generate any specified scenario would have a finite but very small probability of success (Day [7, Chapters 21-24]).

Thus, by proceeding backwards as Leontief advised, a sequence of phases through which history passed can be identified, from which the causal dynamics can be inferred. Looking ahead we can dimly perceive the fundamental instabilities that will eventually drive us from our current system of relationships into a new phase of history. What momentous decisions will be made, what new forms of organization and technology will emerge, and what will remain of those now existing can only be guessed.

Here is something just as baffling as the events that hint at subatomic structure: the emergence of novelty. Modern cosmology describes the universe as a process of change in which successive structures emerge from their predecessors: particles, atoms, molecules, complex compounds, the various stellar bodies and systems, our solar system, the emergence of living things, culminating with humans as the most intelligent and creative among the sentient beings. With humans, novelty follows after novelty with each individual, a unique, complex biochemical, evolutionary process that begins and ends, that is manifestly stable in its persistence, manifestly unstable in its growth, transformation, and death.

\section{Scale and theory}

If there is simplicity somewhere in physics and chemistry, it is not in the microscopic models. It lies more in idealized macroscopic representation. 
In the explanations of process, scale is everything. Nature appears to us as a hierarchy of nested systems: a solar system in the cosmos, our world and its geological dynamics, its biological covering of interacting species; each a physiology of organs and processes, ultimately made up of molecules, in turn comprised of atoms, themselves a baffling quantum manifestation of matter and energy. The behavior of phenomena at a given scale exhibits patterns of movement and transformation that seem to be comprehensible at that scale. The manner in which patterns of movement of systems at one scale depend upon the hierarchy of constituent processes within these systems is often obscure.

Lucky for us! Thus, a thermometer tells a physician what needs to be known about the movement of atoms within a sick patient, and Newton's equations, appropriately augmented with perturbation terms to make up for the departures of nature from mathematical assumptions, guide astronauts to the moon with no knowledge whatsoever of curvature in space-time or of the manner in which electrons distribute their paths through slits in a screen.

At each level in the hierarchy, physical systems work according to laws based on quantitative measures that emerge from phenomena at that level — not all aspects of behavior, but some-those that can be represented by quantitative indexes. Those physicists who think themselves building a single theory of everything will have to find a way to bridge the gaps between the theories that explain events at different scales. As far as I understand the situation at present, not all of the bridges have been built.

As one passes from physical to social science, one finds similar issues confronting the theorist. How can the thought and behavior of individuals at one level be related to the play of chemicals in the brain below and to the discourse among people in a group above? How is the rationality of the individual related to the goals adopted by a family, a business firm, or a unit of government?

In economics, general equilibrium theory characterizes the interaction of individuals or families and business firms, each of whom thoughtfully pursues wants and needs or profits. Using prices, they allocate their resources and operate their production capabilities in the best way, which-given equilibrium prices-leads to compatible choices by everyone. Macroeconomic theorists initially leapt from this characterization to aggregate demand and supply relationships among indexes of goods, money, and prices, leaving implicit any connection to component organizations specified at the microeconomic level (Keynes [8] originated the theory; Tinbergen [15] originated its empirical implementation). The economy so represented is viewed as a macroscopic phenomenon with the hope that laws (or statistical relationships) of aggregate demand and supply will emerge at that level. It is analogous to the way Boyles law describes a relationship between temperature and pressure with no explicit connection to the underlying dynamics of the constituent molecules, or much as Newton's equations of motion applied to the earth and its moon are based solely on the aggregate index of mass with no reference to the complex structures and the dynamics of their movement that make up the two aggregate bodies.

An alternative approach represents the macroscopic economy as a set of identical individuals or, equivalently, as a single person with assumed preferences that order all possible trajectories of aggregate output, consumption, investment, and capital accumulation 
according to the statistical expectation of their discounted values. Such a radically reductionist approach models the growth of the GDP index remarkably well but at the cost of squeezing out any room for differences in the behavior of savings and investment, between labor demand and supply, or in the role of government agencies, or a monetary authority; in short, squeezing out all semblance of coordination or lack thereof (see [3]). It is analogous to a theory of an ideal gas based on a single representative molecule which at a speed near that of light could follow an ergodic trajectory that during any tiny interval of time visited every tiny area of surface a sufficient number of times to produce a pressure that could float a balloon. Has a theorem of that kind been proved? And if so, should we be convinced that it was the right characterization of the macroscopic behavior of an ensemble of gas molecules in a container? Analogously, is it reasonable to characterize an economy as if it were a single omniscient person? Certainly, on the face of it, the answer is obviously "No!" Nonetheless, the estimated "time-preference" parameter can be thought of as a cultural constant that characterizes the average propensity to save in an economy as a whole.

\section{Mathematics and experience}

In continuous dynamics, time is represented by the real numbers, and in discrete dynamics by the integers with any initial condition associated with zero and "now" represented by $t$, a real or integer number, as the case may be. The simplest possible example of reversibility of the index $t$ is in a linear difference equation,

$$
x_{t+1}=a x_{t} .
$$

The variable $x$ after $s$ periods have passed is

$$
x_{t+s}=a^{s} x_{t}
$$

If we think of " $t$ " as "now," then $a^{s} x_{t}$ is what $x$ is expected to be $s$ periods in the future. After those $s$ periods have passed, we can say that $x_{t}$ "occurred" $s$ periods in the past. Thus,

$$
x_{t}=a^{-s} x_{t+s}
$$

This mathematical process, however, does not reverse the order of time. Such an equation represents in a convenient notation a simple growth or decay process but the equation itself is not a simple growth or decay process. It is just symbols on a page that can be manipulated in a way that characterizes a mental image of something salient about an ordering of events that behave in a very specific way over time and that enables us to tell where it is going and whence it came. But when I think of my childhood-no matter how vivid the memory-I have not reversed the passage of time for I continue to age as every moment passes. It is the ordering of memory that makes possible each mental history; it is the ordering of the physiological process of living matter which guarantees that history will cease to exist.

Philosophically minded physicists sometimes appear to confuse the mathematics of a theory with the subject matter of the theory itself (the reversibility of the time index in 
an equation with the reversibility of a physical process of some kind). On the other hand, they sometimes seem to want material things to explain everything such as jumping gravitons holding things together. It is the irreversibility of the physical process that intrigued Prigogine. As I see it, mathematics is never more than a symbolic model of something or some process. It is always abstract, always approximate, always resting ultimately on untested and untestable assumptions.

\section{Mind over matter}

We do not find theories in nature outside the mind, but we can understand and talk to each other about our understanding of how things work. Still more wondrous, the human mind-by thinking - can conjure the image of objects that do not exist, stories of events that might happen in the future, then fashion and follow sequences of actions that make those objects exist, that turn those stories into history. Imagine a molecule in Alexander's white plume, the one he always wore in battle so his troops could always know where he was. Is there any law of physics, or can there ever be a law of physics, that could explain the trajectory of that molecule through time? Alexander's example proves that in history human volition has the potential to make things happen, to cause events ("Wilken ... pointed out this moment of decision [to move on Egypt instead of pursuing Darius] is one of history's great proofs that individuals, not mere economic forces, can change the destinies of mankind" [13, page 116]).

This capacity of mind is not just wondrous, it is also ordinary. Every sane person possesses it to some degree, for every person thinks of and chooses to do things they have never previously done. Every person recognizes degrees of freedom that provide scope for choice, is aware of constraints that bound potential action, and considers preferences that connect potential actions with the anticipated satisfaction of needs and wants. Every sane person exercises self-control that guides action along chosen paths, yet possesses the flexibility to change course in midstream in response to developing external situations that induce a reconsideration in the perceived possibilities and anticipated satisfactions.

Economists have formalized these attributes of mind in an abstract mathematical theory of rational choice, progressively refining and generalizing it. Incorporated into the mathematical model of a general equilibrium, it represents in an abstract and idealized way a decentralized market economy in a state of perfect coordination, mediated by equilibrium prices. It has the practical significance of hinting how and why market economies have flourished relative to the nonmarket alternatives.

I say "hinting" because, though it captures the rational aspect of individual human action, it does so at the expense of inadequately accounting for the boundedness and fallibility of rational thought and the evolutionary character of economic life. Rational thought is fallible because knowledge of options and the processes that must be used to execute plans is incomplete; it is fallible because choosing is a problem of constrained optimization, a problem that can usually be solved only approximately, or not at all, the first often most difficult step being to find a solution that is feasible.

The result is that human action cannot normally be based on formal thinking but on other modes for determining a course of action: imitating others, trial and error search or experimentation, consulting an authority, doing what you did before as long as it "works," 
or acting on a "hunch" or intuition, or even thoughtless impulse. Economic science is rapidly expanding its inquiry into these alternative modes of behavior. Such inquiries are the economist's equivalent of looking inside the atom.

We are a social species so many, if not most, of our actions are interactions with others. We begin in some sort of "family," go to schools, play in sports and music groups, work under the direction of others and/or in cooperation with others in some sort of hierarchical structure, or in competition with other individuals or groups. The competitive equilibrium defined by the general economic equilibrium model takes account of interaction of individuals in terms of flows of goods but without any other interchange among them. The theory of games has focused on the interaction of individuals using strategies that are optimal in the context of rather narrowly drawn competitive situations. Organization theorists, however, have investigated the inner workings of large scale organizations comprised of individuals performing varied tasks, arranged in a cooperative hierarchy, arriving in this way at a sort of political science of the business enterprise involving structures of authority and power, that is, of governance (Commons (1950), $[11,14,16])$.

The point to be emphasized here is that economic phenomena introduce volition in a fundamental way. The atoms (people), governed by volition, form molecules and compounds (households, firms, government agencies) according to mentally emergent laws that evolve: laws governed by legal or quasilegal processes with new institutions being invented and with existing ones undergoing continual revision and transformation.

All what we want to say is that the operation of mind governs the flow of material in the economic world. It is as if atoms could decide what kind of atom they want to be: what valence, what atomic weight; could decide with whom they want to form molecules; could invent completely new molecules that never existed before; or could set off motion into orbits of their choosing and return to some other trajectory at will. Those who hope to discover laws of human behavior will have to deal with the dynamics of organizations and the mechanisms that lead people to obey or violate the laws they create for themselves.

\section{Development}

Far from equilibrium ... new processes set in ....

Prigogine [12, page 67]

To encompass fundamental aspects of physical and human nature, economic theorists must commit themselves to a dynamic, evolutionary point of view. In so doing, it is unlikely that a single unified framework will serve the purpose. As in physics, distinct theoretical relationships have to be developed for the distinct levels at which action can be measured. If we take the individual to be the basic atom of economic phenomena, then the micro theory is concerned with what, why, and how people choose. At the macro level is the economics of a nation based on indexes of aggregated micro variables: GDP, total investment and consumption, measures of total capital and productivity, population, working age population, the employed and unemployed, total government spending, and the total money supply. In between lies the theory of organizational structures, households, 
business firms, and government agencies. The explanation of behavior at this level is in between the micro and the macro, thus, sometimes referred to as meso-economics.

Mechanical phenomena-both physical mechanisms and mathematical theorieshave played fundamental roles in economic development. The direct result of creative intelligence is that their progeny have accumulated to such an extent as to dominate the environment within which further human development takes place. Alluded to briefly above was an explanation of how economic choice operates on alternative technologies and drives human societies through phase transitions that take place one after another. The process is modeled using the mathematical tools of multiple phase dynamics (see $[6,7])$. Examples can be specified in which given phase structures can be repeated in a cyclic or irregular sequence reminiscent of the Hindu paradigm, a history repeating its former structures again and again. In reality, given the irreversibility of chemical processes and "a fortiori biological processes," cycles, if indeed they exist at all, must inevitably be interrupted (see [12, page 212]).

Even if the number of possible phase structures that exist at any one time is finite, the creative intelligence can always be counted on to add more to the repertoire. We will always be pioneers, each generation opening up a previously inexperienced new age. Our phase progressions will form unique sequences; the future perpetually producing uncertainty and novelty.

On the basis of reflections like these, it has been observed that physics, chemistry, economics, ..., science in general is not so far removed from literature and poetry. Ilya had a great love of the arts as well as the sciences. His work as a physicist seems to have been less - and more-than a quest for a theory of everything. His approach may not have built bridges between all the levels of physical and social reality. He did build a bridge between the various ways the human mind attempts to comprehend experience: an understanding of the evolutionary and uncertain character that is common to the material world and to all of life that has emerged from it.

\section{References}

[1] P. M. Allen, W. L. Schieve, and R. N. Adams (eds.), Special volume on modeling complex systems, European Journal of Operations Research 30 (1987), no. 3.

[2] Arrian (Flavius Arrianus Xenophon), The Campaigns of Alexander, Penguin Books, Harmondsworth, 1971, translated by Aubrey de Selincourt.

[3] T. F. Cooley and E. C. Prescott, Economic growth and business cycles, Frontiers of Business Cycle Research (T. F. Cooley, ed.), Princeton University Press, Princeton, 1995, Chapter 1.

[4] R. Crosby (ed.), Cities and Regions as Nonlinear Decision Systems, Westview Press, Colorado, 1983.

[5] R. H. Day, Nonlinear dynamics and evolutionary economics, Nonlinear Dynamics and Evolutionary Economics (P. Chen and R. Day, eds.), Oxford University Press, New York, 1993, Chapter 3.

[6] _ Multiple-phase economic dynamics, Nonlinear and Convex Analysis in Economic Theory (Tokyo, 1993), Lecture Notes in Economics and Mathematical Systems, vol. 419, Springer-Verlag, Berlin, 1995, pp. 25-45.

[7] _ The Divergent Dynamics of Economic Growth: Studies in Adaptive Economizing, Technological Change, and Economic Development, Cambridge University Press, Cambridge, 2004. 
[8] J. M. Keynes, The General Theory of Employment, Interest and Money, Harcourt Brace and Company, New York, 1936.

[9] W. W. Leontief, When should history be written backwards, Economic History Review Second Series 16 (1963).

[10] Essays in Economics: Theories and Theorizing, Oxford University Press, London, 1966, Chapter 2.

[11] J. G. March and H. A. Simon, Organizations, John Wiley \& Sons, New York, 1958.

[12] I. Prigogine, From Being to Becoming: Time and Complexity in the Physical Sciences, W. H. Freeman, New York, 1980.

[13] M. Renault, The Nature of Alexander, Pantheon Books, New York, 1975.

[14] H. A. Simon, Administrative Behavior: A Study of Decision Making Processes in Administrative Organization, The Free Press, New York, 1957.

[15] J. Tinbergen, Statistical Testing of Business Cycle Theories, League of Nations, Geneva, 1939, reprinted in 1962 by Agathon Press, New York.

[16] O. E. Williamson, Economic Organizations: Firms, Markets and Policy Control, New York University Press, New York, 1986.

Richard H. Day: Department of Economics, University of Southern California, Los Angeles, CA 90089-0253, USA

E-mail address: rday@usc.edu 


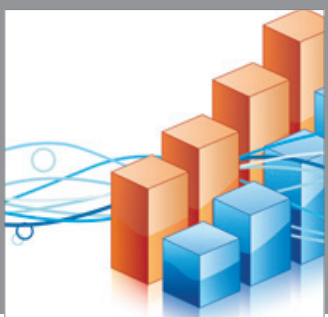

Advances in

Operations Research

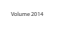

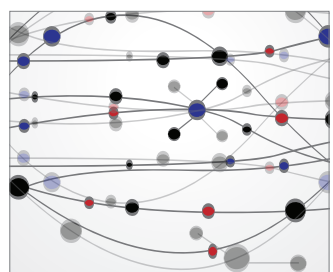

\section{The Scientific} World Journal
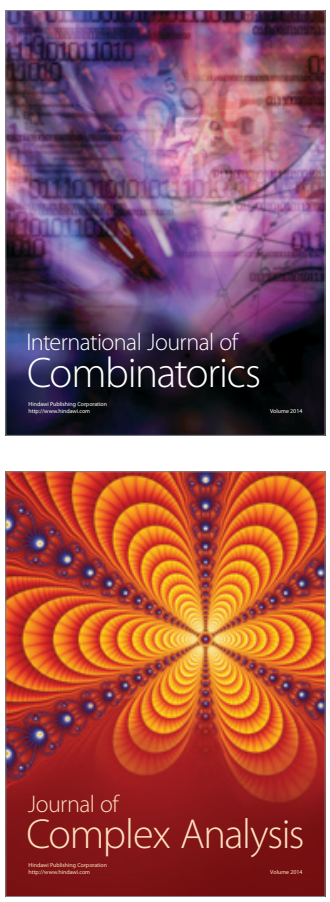

International Journal of

Mathematics and

Mathematical

Sciences
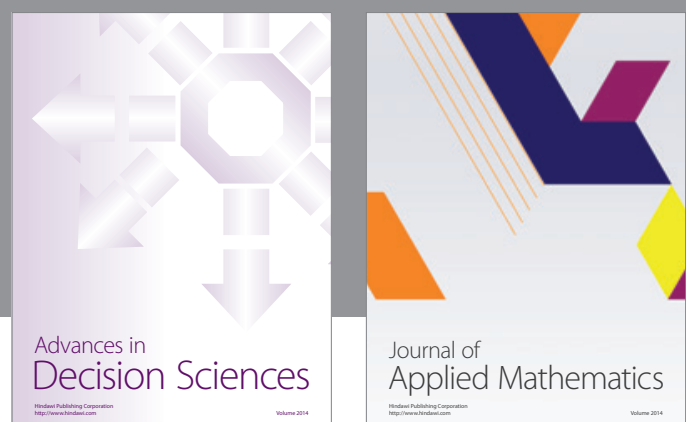

Journal of

Applied Mathematics
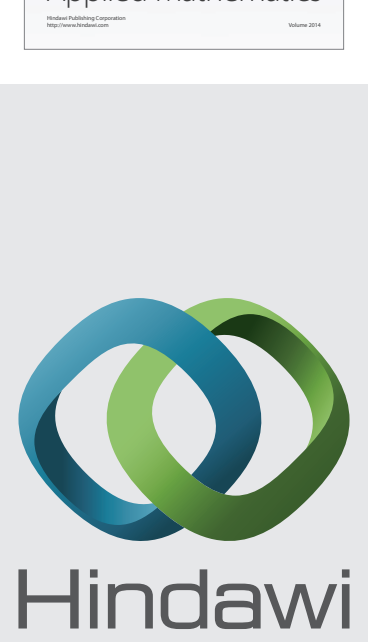

Submit your manuscripts at http://www.hindawi.com
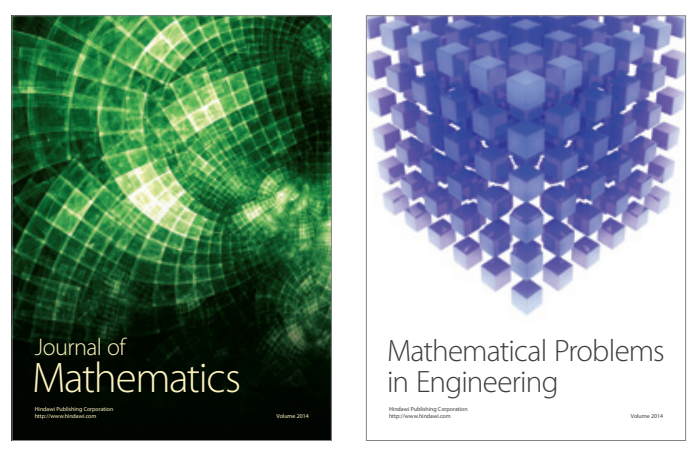

Mathematical Problems in Engineering
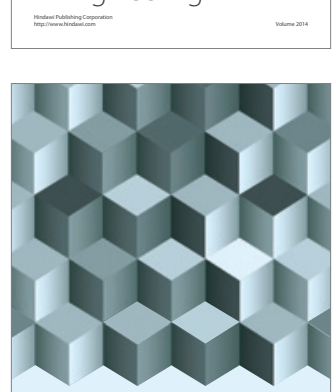

Journal of

Function Spaces
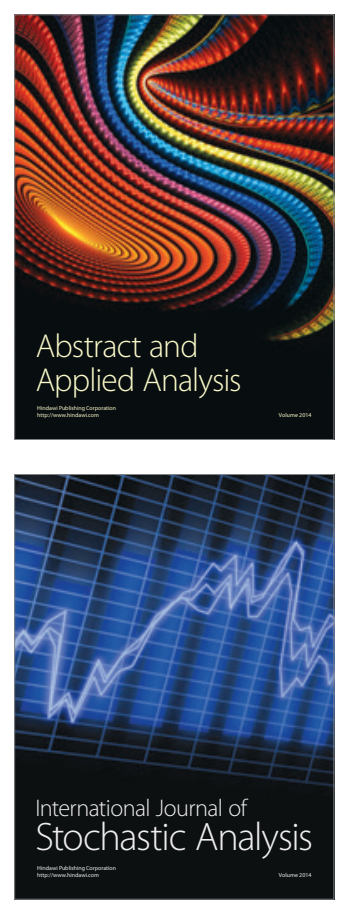

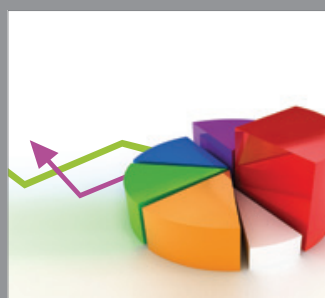

ournal of

Probability and Statistics

Promensencen
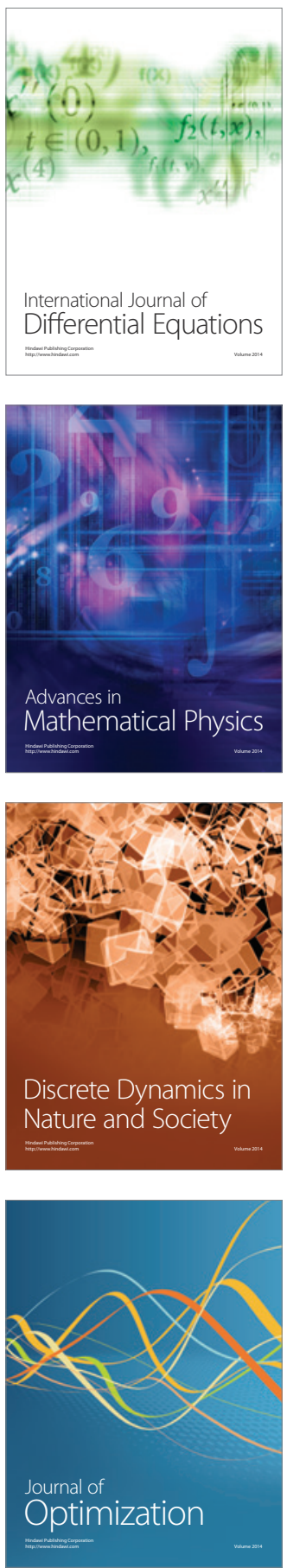